(c) American Dairy Science Association, 2002.

\title{
Effect of Heat Stress on Nonreturn Rate in Holsteins: Fixed-Model Analyses
}

\author{
O. Ravagnolo ${ }^{1}$ and I. Misztal \\ Department of Animal Science, \\ University of Georgia, Athens 30602
}

\begin{abstract}
The objective of this study was to examine the relationship between reproductive traits and heat stress. Nonreturn rate at $45 \mathrm{~d}$ (NR45) was analyzed in a fixedeffect model that included the temperature-humidity index (THI) from a nearby weather station as a measurement of heat stress. Data consisted of 150,200 first inseminations at first and later parities of 110,860 Holstein cows from 550 herds in Georgia, Tennessee, and Florida with weather information from 16 weather stations. THI on the day of the insemination, $2 \mathrm{~d}$ prior, 5 $\mathrm{d}$ prior, 5, 10, 20, and $30 \mathrm{~d}$ after insemination were studied as independent variables. The THI on the day of insemination showed the highest effect on NR45, followed by $2 \mathrm{~d}$ prior, $5 \mathrm{~d}$ prior, and $5 \mathrm{~d}$ after insemination, but no relationship was found with THI at 10, 20, and $30 \mathrm{~d}$ after insemination. NR45 showed a decrease of 0.005 per unit increase in THI on the day of insemination for THI $>68$. First and later parities presented similar thresholds but responded differently to an increase in THI, with NR45 being significantly lower and more susceptible to increases of THI in cows in their first parity than in later parities $(0.008$ vs. 0.005 decrease). Threshold for sensitivity to heat stress changed with the states, with Florida, Georgia, and Tennessee having thresholds of 70,70, and 66, respectively. The decrease in NR45 per unit increase of THI was 0.007, 0.005, and 0.006 for Florida, Georgia, and Tennessee, respectively. With respect to only the Florida data, the final fixed-effect model used was NR45 = herd(year) + month (year) + month (year) + age(parity) + days in milk $+100 \mathrm{~d}$ milk + THI + error. Animals with more than $150 \mathrm{~d}$ in milk (DIM) had a 0.16 lower NR45 than animals with less than 60 DIM at insemination. Lower milk-producing animals showed 0.08 higher NR45 than higher-producing animals. A difference of 0.10 in NR45 was observed between THI lower than 70 and THI 84 .
\end{abstract}

Received August 13, 2001.

Accepted October 16, 2002

Corresponding author: I. Misztal; e-mail: ignacy@uga.edu.

${ }^{1}$ Current address: Instituto Nacional de Investigación Agropecuaria Las Brujas, Uruguay.
This variation in NR45 caused by THI changes is sufficient to merit further studies to examine genetic components of heat tolerance for this trait.

(Key words: heat stress, nonreturn rate, temperaturehumidity index, Holstein)

Abbreviation key: $\mathbf{N R}=$ nonreturn rate, $\mathbf{T H I}=$ temperature-humidity index.

\section{INTRODUCTION}

Heat stress is responsible for important economic losses in the dairy industry. At thermoneutrality, the cow can maintain homeostasis without excessive use of energy for thermoregulation; hence, energy is available for maintaining optimum conditions of health and performance (Yousef, 1985). When heat load increases, the animal has direct energy to eliminate excessive heat in order to maintain internal thermal balance. This is not always sufficient. Consequently, body temperature increases, which in turn affects various body functions. There have been many studies on the effect of heat stress on both reproduction and production (see review by Wolfenson et al., 2000). Significantly lower conception rates have been observed in cows with above-normal body temperatures at the time of insemination because of low fertilization and a high incidence of embryonic deaths (Fuquay, 1981). The viability of both the ova and the spermatozoids is significantly lowered when body temperatures are higher than normal, which results in lowered fertility. High temperatures affect the development of young embryos, which are most vulnerable in the first few days of life (Fallon, 1962; Stott and Williams, 1969). There is also a negative effect on the incidence of standing estrous and on the intensity and duration of estrous. In addition, it has been observed that heat stress might prevent or delay ovulation (Her et al., 1988; Wilson et al., 1998).

Heat stress can be moderated through various management techniques, such as sprinklers and fans (Armstrong, 1994). Such measures appear to be effective in reducing the effect of heat stress up to a certain degree. These measures will not eliminate the effect and are expensive to implement. Much effort has been put into 
finding breeds or crossbreds that are heat tolerant. Until now, this effort has not been successful in the dairy industry (McDowell et al., 1996). However, Ravagnolo and Misztal (2000) found sufficient genetic variability to allow selection for heat tolerance for milk, fat, and protein production within Holsteins. They defined a regular production ability, which is the genetic ability to produce milk in the absence of heat tolerance, and a heat tolerance genetic effect, which is the genetic ability to avoid reduction in milk yield when exposed to heat stress. Because the genetic correlation between heat tolerance and regular production ability was -0.33 , it is possible to select for both traits simultaneously. This may also be the case for reproductive traits, which seem to be even more susceptible to heat stress than production traits. Gwazdauskas et al. (1975) found that the two most important weather variables determining conception rate were maximum temperature on the day after insemination and rainfall on the day of insemination. However, Ingraham et al. (1974) found that average temperature humidity index (THI) $2 \mathrm{~d}$ before insemination had a higher relationship than the same variable on the day of insemination and on the day after insemination.

Many different traits are being used to evaluate reproductive performance. In this study, the focus will be on nonreturn rate (NR), because it is currently used in several countries as a measure of reproductive ability (De Jong, 1997; Hyppänen and Juga, 1997). In this trait, success or failure is recorded at a given time after insemination. If there is no record of further inseminations for the same cow in the same lactation within a certain time limit, success in conception is assumed. Because a cow can return to service because of failure of conception or embryonic death at different stages, NR might be influenced not only by heat stress on the day of the service but also by heat stress on previous days and on some days after insemination (Stott and Williams, 1969; Her et al., 1988; Wilson et al., 1998).

Heat stress can be measured many ways. In a previous study, THI was used to analyze the effect of heat stress on production traits (Ravagnolo et al., 2000). The index was constructed using maximum temperature and minimum humidity from an assigned nearby weather station. This model allows national genetic evaluations for heat stress without recording new information because previously available weather station data can be used. The objective of this paper was 1) to establish on which day heat stress has the greatest impact on NR 45 (NR45) with the use of THI proposed by Ravagnolo et al. (2000); 2) to establish the relationship between THI and NR45; and 3) to develop a fixedeffect model to study the genetics of heat stress for NR45.

\section{MATERIALS AND METHODS}

\section{Data}

Reproductive data consisted of 150,200 first inseminations for first and later parities of 110,860 Holstein cows from 550 herds in Georgia, Tennessee, and Florida from 1995 to 1999. Nonreturn rate at $45 \mathrm{~d}$ was calculated only for first inseminations, with a value of 1 assigned to cows that did not return to insemination (i.e., assumed pregnant) and 0 for cows that were inseminated a second time within $45 \mathrm{~d}$. Cows had to be between 24 and 83 mo of age and between the first and fourth lactation. Only cows between 30 and 200 DIM were included.

This data set was augmented with THI on the day of the insemination, $2 \mathrm{~d}$ prior, $5 \mathrm{~d}$ prior, $5,10,20$, and 30 $\mathrm{d}$ after insemination. The THI came from the weather station closest to the herd in Georgia, Tennessee, and Florida. To assign a weather station to each herd, distances between each herd and each weather station were calculated using latitude and longitude assigned to each herd and weather station through their zip code, where the distance (in miles) between location 1 and 2 is

$$
\begin{aligned}
\operatorname{dist}_{(1,2)}= & 3963 *\left(\operatorname { a c o s } \left(\sin \left(\text { lat }_{1}\right) * \sin \left(\text { lat }_{2}\right)+\right.\right. \\
& \left.\cos \left(\text { lat }_{1}\right) * \cos \left(\text { lat }_{2}\right) \cos \left(\operatorname{lon}_{2}-\operatorname{lon}_{1}\right)\right)(21) .
\end{aligned}
$$

The weather station with less distance to each herd was assigned, and this resulted in 16 different weather stations assigned to the 550 herds. From the hourly data from each weather station, maximum daily temperature and minimum daily humidity were extracted, with which THI was calculated

$$
\begin{aligned}
\operatorname{THI}(\mathrm{t}, \mathrm{h})= & 9 / 5 \mathrm{t}+32-11 / 2(1-\mathrm{h})(9 / 5 \mathrm{t}-26) \text { (NOAA, } \\
& 1976),
\end{aligned}
$$

where $\mathrm{t}$ is the maximum daily temperature in ${ }^{\circ} \mathrm{C}$, and $\mathrm{h}$ is the minimum daily relative humidity (Ravagnolo et al., 2000). Tables 1 and 2 show the distribution of the dataset and a summary of the basic statistics.

\section{Statistical Analysis}

Twenty age classes were defined by every 3-mo interval, starting at 24 mo of age. Days in milk classes were defined as one class for every $30 \mathrm{~d}$ (the first class starting at DIM 30), resulting in five classes (the last class included data from 150 to 200 DIM). Milk production classes were defined by total production in the first 3 mo and resulted in five classes. Data with THI $<50$ and $>84$ were eliminated, and classes that included THI every two units were constructed. 
Table 1. Data distribution per state and basic statistics.

\begin{tabular}{lrccc}
\hline Characteristics & Total & Georgia & Florida & Tennessee \\
\hline Observations & 150,201 & 54,463 & 57,195 & 38,543 \\
Herds & 550 & 196 & 94 & 260 \\
Cows & 11,0860 & 39,217 & 43,382 & 28,261 \\
First lactation & 58,455 & 21,287 & 22,865 & 14,303 \\
Second lactation & 45,716 & 16,954 & 16,988 & 11,770 \\
Third lactation & 29,876 & 10,578 & 11,335 & 7963 \\
Fourth lactation & 16,154 & 5640 & 6007 & 4507 \\
THI $^{1}$ avg. & 68.17 & 66.87 & 71.36 & 65.25 \\
THI sd. $_{\text {NR45 }}^{2}$ avg. & 8.78 & 8.56 & 7.76 & 8.91 \\
NR45 sd. & 0.58 & 0.61 & 0.51 & 0.64 \\
& 0.49 & 0.49 & 0.50 & 0.48 \\
\hline
\end{tabular}

${ }^{1} \mathrm{THI}=$ Temperature-humidity index.

${ }^{2} \mathrm{NR} 45=$ Nonreturn rate at $45 \mathrm{~d}$ after insemination.

The objective of model 1 was to determine at which day heat stress has a greater influence on NR45. The fixed-effect model was defined as

$$
\begin{aligned}
\mathrm{y}_{\mathrm{ijklmnopq}}= & \mathrm{h}_{\mathrm{i}}\left(\mathrm{yr}_{\mathrm{j}}\right)+\mathrm{m}_{\mathrm{k}}\left(\mathrm{yr}_{\mathrm{j}}\right)+\mathrm{a}_{\mathrm{l}}\left(\mathrm{p}_{\mathrm{m}}\right)+\operatorname{dim}_{\mathrm{n}}+ \\
& \mathrm{m}_{\mathrm{o}}+\mathrm{THI}_{\mathrm{p}}+\mathrm{e}_{\mathrm{ijklmnopq}},
\end{aligned}
$$

where $y_{\mathrm{ijklmnopq}}$ is the nonreturn rate $45(0$ and 1$)$ in herd $\mathrm{i}$, year $\mathrm{j}$, month $\mathrm{k}$, class $\mathrm{l}$, parity class $\mathrm{m}$, DIM class $n$, milk production class 0 , and THI class $p ; h_{i}$ is effect of herd $\mathrm{i}(\mathrm{i}=1, . ., 550)$ nested within year $\mathrm{yr}_{\mathrm{j}}(\mathrm{j}=$ 1995-1999); $\mathrm{m}_{\mathrm{k}}$ is effect of month $\mathrm{k}(\mathrm{k}=1,12)$ nested within year, $a_{1}$ is the effect of age $l(l=1,20)$ nested within parity; $\mathrm{p}_{\mathrm{m}}$ is the effect of parity $\mathrm{m}(\mathrm{m}=1-4)$; $\operatorname{dim}_{n}$ is effect of DIM class $n(n=1,5) ; m_{0}$ is effect of milk production class o $(o=1-5)$; $\mathrm{THI}_{\mathrm{p}}$ is effect of THI class $(\mathrm{p}=1-18)$ alternatively at $\mathrm{d} 0,-5,-2,+5,+10,+20$, and +30 after insemination; and $\mathrm{e}_{\mathrm{ijk} \text { lmnopq }}$ is residual.

Table 2. Distribution, mean and standard deviation of nonreturn rate at $45 \mathrm{~d}$ (NR45) for temperature-humidity index (THI) classes.

\begin{tabular}{lccl}
\hline & \multicolumn{3}{c}{ NR45 } \\
\cline { 2 - 4 } THI & Observations & Mean & Std. dev. \\
\hline 50 & 1866 & 0.670 & 0.470 \\
52 & 4173 & 0.658 & 0.475 \\
54 & 5407 & 0.648 & 0.478 \\
56 & 6128 & 0.650 & 0.478 \\
58 & 7358 & 0.639 & 0.480 \\
60 & 8264 & 0.652 & 0.476 \\
62 & 9354 & 0.622 & 0.485 \\
64 & 9767 & 0.628 & 0.483 \\
66 & 10,356 & 0.615 & 0.487 \\
68 & 11,387 & 0.609 & 0.488 \\
70 & 11,646 & 0.592 & 0.491 \\
72 & 11,684 & 0.578 & 0.494 \\
74 & 11,606 & 0.546 & 0.498 \\
76 & 9766 & 0.532 & 0.499 \\
78 & 10,194 & 0.515 & 0.500 \\
80 & 8876 & 0.485 & 0.500 \\
82 & 7941 & 0.441 & 0.496 \\
84 & 4428 & 0.414 & 0.493 \\
\hline
\end{tabular}

Other fixed effects fitted by several authors are AI Center and/or insemination technician (Boichard et al., 1997; Miglior et al., 1997). Because of a lack of information, these effects were not included in our model. Once the day with the highest effect of THI on NR45 was determined, the same model was used to analyze differences in the response of NR45 to THI in different states and for different lactations. Five datasets were used: 1) information from Georgia; 2) from Tennessee; 3) from Florida; 4) first lactation for all states together; and 5) second, third, and fourth lactation for all states together. All analyses were conducted with the GLM procedure of SAS (1996).

\section{RESULTS AND DISCUSSION}

Table 3 shows the results for model 1 with the complete data set. The THI at the day of the service, $2 \mathrm{~d}$ prior, and $30 \mathrm{~d}$ after service had a higher sum of squares and consequently a higher $\mathrm{R}^{2}$ than the other days analyzed. Figure 1 shows the relationship between least

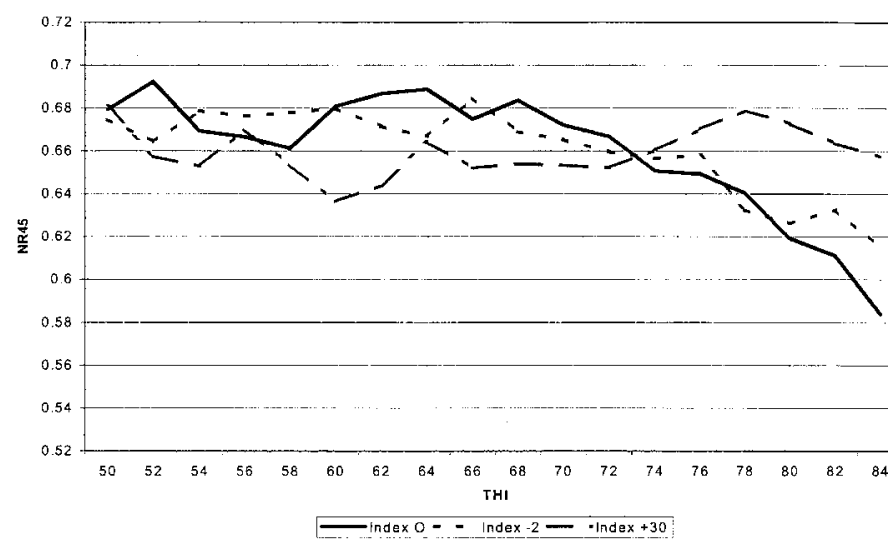

Figure 1. Effect of temperature-humidity index (THI) on nonreturn rate at $45 \mathrm{~d}$ (NR45) for THI measured $-2,0$ and $30 \mathrm{~d}$ relatively to conception. 
Table 3. Results from the analysis of variance for temperature-humidity index (THI) at different days relative to conception obtained from the complete dataset.

\begin{tabular}{llllllrl}
\hline & $\begin{array}{l}5 \mathrm{~d} \\
\text { prior }\end{array}$ & $\begin{array}{l}2 \mathrm{~d} \\
\text { prior }\end{array}$ & $\begin{array}{l}\text { Day of } \\
\text { service }\end{array}$ & $\begin{array}{l}5 \mathrm{~d} \\
\text { after }\end{array}$ & $\begin{array}{l}10 \mathrm{~d} \\
\text { after }\end{array}$ & $\begin{array}{l}20 \mathrm{~d} \\
\text { after }\end{array}$ & $\begin{array}{l}30 \mathrm{~d} \\
\text { after }\end{array}$ \\
\hline Total & 23,217 & 23,217 & 23,217 & 23,217 & 23,217 & 23,217 & 23,217 \\
Model & 3110 & 3116 & 31,250 & 3111 & 3109 & 3111 & 3112 \\
Error & 20,106 & 20,101 & 20,092 & 20,106 & 20,107 & 20,106 & 20,104 \\
THI SS III & 6.4 & 11.9 & 20.5 & 6.6 & 5.3 & 6.5 & 8.3 \\
$\mathrm{R}^{2}$ & 0.134 & 0.134 & 0.135 & 0.134 & 0.134 & 0.134 & 0.134 \\
\hline
\end{tabular}

squares means of NR45 for THI on the day of insemination, $2 \mathrm{~d}$ before and $30 \mathrm{~d}$ after insemination, and NR45. Although THI at $30 \mathrm{~d}$ after insemination has one of the largest sum of squares in the study, it did not show any clear relationship between NR45 and increasing THI. For THI $2 \mathrm{~d}$ before and on the day of the service, there is a clear relationship between increasing THI and NR45. The relationship is somewhat linear until around THI, 68 at which point NR45 starts decreasing. Of these two days, THI on the day of the service shows a more linear relationship to changes in NR45 than THI $2 \mathrm{~d}$ before insemination. This seems to suggest that, for our dataset at least, THI has a greater effect on NR45 through lowering conception at the moment of insemination than on embryonic deaths. Results from a study by Ingraham et al. (1974) indicated that the highest correlated variable to conception rate was average THI $2 \mathrm{~d}$ before breeding, followed by the day after breeding, the day before conception, and the least correlated was the day of breeding. However, THI on the day of breeding showed a greater slope than the day after and the day before insemination, second only to the slope of average THI $2 \mathrm{~d}$ before insemination. The authors observed the discrepancies in results and cautioned against designating one measure as the most important weather

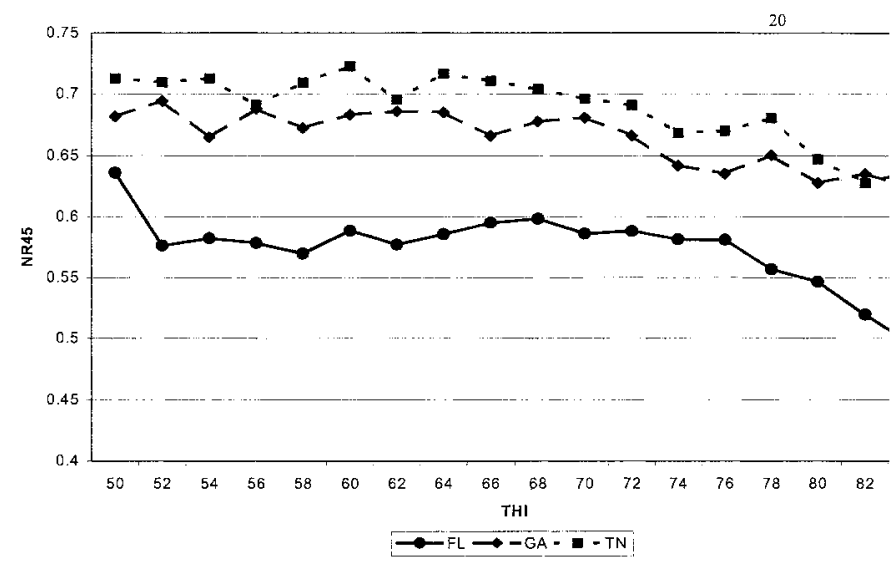

Figure 2. Effect of temperature-humidity index (THI) on nonreturn rate at $45 \mathrm{~d}$ (NR45) in Florida, Georgia, and Tennessee. index, because such measures can change depending on geographical region.

There is not sufficient information contained in NR45 to conclude anything about the effect of heat stress on estrus, because by definition, all observations used are from cows that have been inseminated, that is, have shown estrus.

NR45 seems to be rather stable until THI 68 , at which point there is a loss of 0.005 of NR45 per unit increase of THI on the day of the insemination. Because this THI better explained the loss of NR45, for all further analysis THI on the day of the insemination was used.

Least squares means of THI for NR45 on the day of insemination for the three states is shown in Figure 2. NR45 is significantly lower in Florida than in Georgia and Tennessee. For Georgia and Florida, NR45 starts to decrease because of increasing THI at a threshold of THI around 70, whereas for Tennessee, the threshold is around THI 66. In addition, the three states show different responses to increases of THI after the threshold with a loss of NR45 of 0.006, 0.005, and 0.007 for Tennessee, Georgia, and Florida, respectively, with FL showing the highest influence and the most linear relationship.

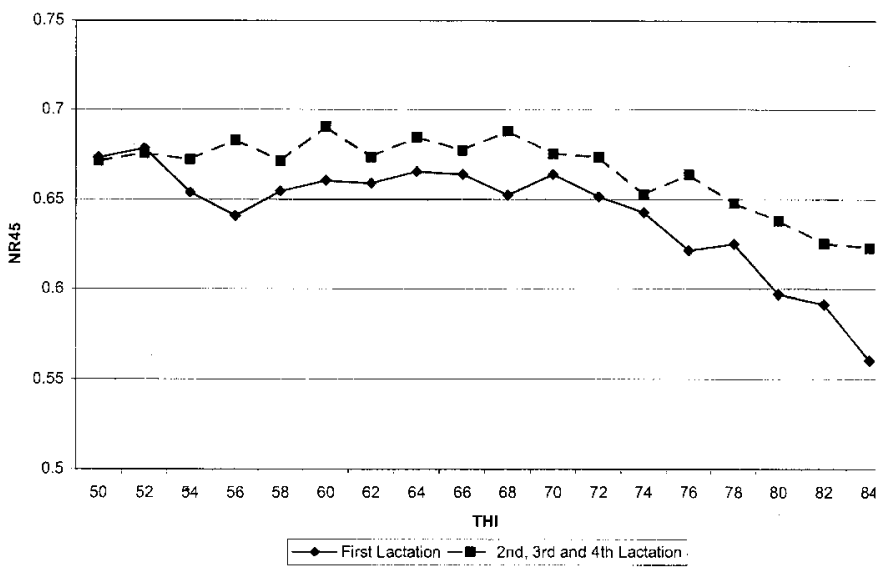

Figure 3. Effect of temperature-humidity index (THI) on nonreturn rate at $45 \mathrm{~d}$ (NR45) for first and later lactations. 
Table 4. Results from the analysis of variance of the dataset with observations from Florida only.

\begin{tabular}{lrcc}
\hline & df & Type III SS & $P>F$ \\
\hline Herd(year) & 295 & 923.90 & 0.0001 \\
Month(year) & 55 & 331.10 & 0.0001 \\
Age-lactation & 35 & 12.04 & 0.0171 \\
DIM & 4 & 77.32 & 0.0001 \\
Milk & 4 & 27.17 & 0.0001 \\
THI $^{2}$ & 17 & 12.22 & 0.0001 \\
\hline
\end{tabular}

${ }^{1} \mathrm{SS}=$ Sums of squares.

${ }^{2} \mathrm{THI}=$ Temperature-humidity index.

Inseminated first-lactation cows responded differently to increases of THI, as is shown by Figure 3. First-lactation cows had lower NR45 than cows in later lactations, which was expected because the second pregnancy is the most critical one because of the energy requirement of the lactation combined with the energy requirements of continuing growth. The threshold for both groups of data was similar, but first-lactation cows are more sensitive to each unit increase of THI than later-lactation cows. The decrease in NR45 caused by each unit increase of THI after 70 was 0.008 for firstlactation cows and 0.005 for second-, third-, and fourthlactation cows. The higher sensitivity to heat stress in first-lactation cows agrees with findings that animals already subjected to stress are more sensitive to heat stress. For example, high-yielding cows are much more sensitive to increases in temperature and humidity than lower-producing cows (Bianca, 1965). Despite the different response of first-lactation cows and later-lactation cows to increases in THI, we decided to analyze the Florida data with all parities included in order to simplify the analysis and to not diminish the size of the data set for the genetic analyses.

Table 4 shows the sum of squares of the model for the Florida dataset. As can be observed, all effects included

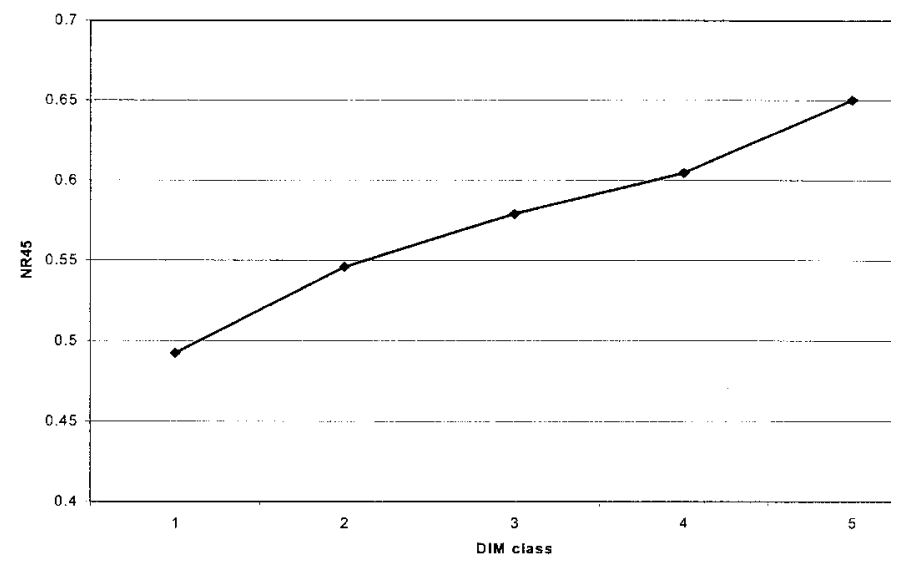

Figure 4. Effect of DIM on nonreturn rate at $45 \mathrm{~d}$ (NR45).

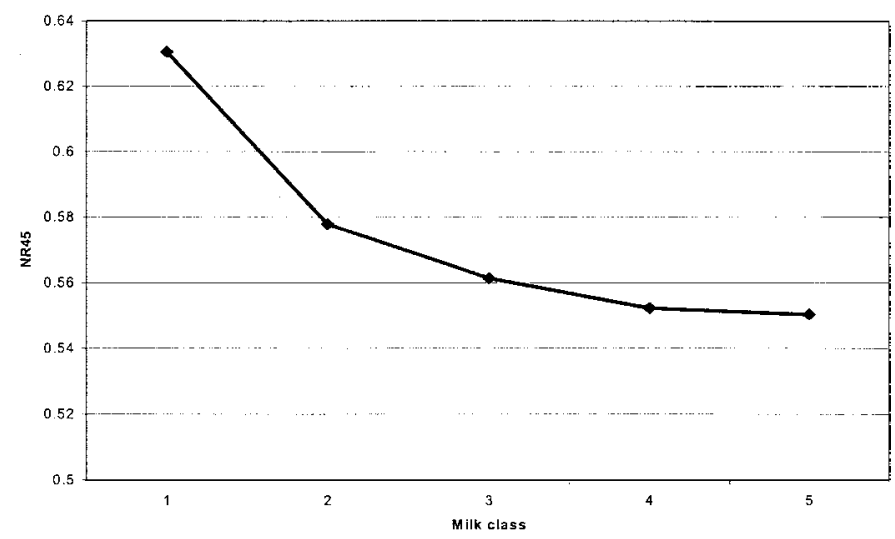

Figure 5. Effect of milk yield on nonreturn rate at $45 \mathrm{~d}$ (NR45).

were highly significant. The effect of DIM and of milk production on NR45 are shown in Figures 4 and 5. The effect of DIM is larger than the effect of milk production in the first 3 mo of lactation, with a difference of 0.15 between the lowest and highest DIM and a difference of 0.08 between the highest and lowest milk production. For this data set we can observe from Figure 2 that there is a difference of almost 0.1 between absence of heat stress $(\mathrm{THI}<70)$ and exposure to high heat stress $(\mathrm{THI}=84)$. This variation might be sufficient to capture genetic variability of heat tolerance using THI from nearby weather stations.

\section{CONCLUSIONS}

It is possible to, at least partially, account for the effect of heat stress on NR45 with the use of THI constructed from public weather station data. THI on the day of insemination seems to be the most informative variable to quantify heat stress of the seven different variables studied.

\section{ACKNOWLEDGMENTS}

Appreciation is expressed to Gerrit Hoogenboom (UGA) for providing weather data and assistance during this study, George Wiggans (USDA) for providing production data and for John Clay, Dairy Records Management Systems, Pennsylvania DHIA and AgSource for providing reproductive data. This study was partly supported by the Holstein Association of America.

\section{REFERENCES}

Armstrong, D. V. 1994. Heat stress interaction with shade and cooling. J. Dairy Sci. 77:2044-2050.

Bianca, W. 1965. Reviews of the progress of dairy science. Dairy Res. 32:291-345. 
Boichard, D., A. Barbat, and M. Briend. 1997. Genetic evaluation for fertility in French dairy cattle. Interbull Mtg. Grub. Uppsala, Interbull Bull No. 18.

De Jong, G. 1997. Index for daughters' fertility in the Netherlands. Interbull Mtg. Grub. Uppsala, Interbull Bull No. 18.

Fallon, G. R. 1962. Body temperature and fertilization in cow. J. Reprod. Fertil. 3:116.

Fuquay, J. W. 1981. Heat stress as it affects animal production. J. Anim. Sci. 52(1):164-174.

Gwazdauskas, C. J., C. J. Wilcox, and W. W. Thathcer. 1975. Environmental and managemental factors affecting conception rate in a subtropical climate. J. Dairy Sci. 58:88-92.

Her, E., D. Wolfenson, I. Flamenbaum, Y. Folman, M. Kaim, and A. Berman. 1988. Thermal, productive and reproductive responses of high yielding cows exposed to short-term cooling in summer. J. Dairy Sci. 71:1085-1092.

Hyppänen, K., and J. Juga. 1997. Environmental and genetic effects on the 60-day nonreturn rate in Finnish AI bulls. Interbull Mtg. Grub. Uppsala, Interbull Bull No. 18.

Ingraham, R. H., D. D. Gillette, and W. D. Wagner. 1974. Relationship of temperature and humidity to conception rate of Holstein cows in subtropical climate. J. Dairy Sci. 57:476-481.

McDowell, R. E., J. C. Wilk, and C. W. Talbott. 1996. Economic viability of crosses of Bos taurus and Bos indicus for dairying in warm climates. J. Dairy Sci. 79:1292-1303.

Miglior, F., F. Pizzi, and N. Guaita. 1997. Effect of environmental factors on non return rate in Italian Holstein-Friesians. Interbull Mtg. Grub. Uppsala, Interbull Bull No. 18.
NOAA. 1976. Livestock hot weather stress. U.S. Department of Commerce, National Oceanic and Atmospheric Administration, National Weather Service Central Region. Regional Operations Manual Letter C-31-76.

Ravagnolo, O., I. Misztal, and G. Hoogenboom. 2000. Genetic component of heat stress in dairy cattle-development of heat index function. J. Dairy Sci. 83:2120-2125.

Ravagnolo, O., and I. Misztal. 2000. Genetic component of heat stress in dairy cattle-parameter estimation. J. Dairy Sci. 83:21262130.

SAS User's Guide: Statistics, Version 6.12 Edition. 1996. SAS Inst. Inc., Cary, NC.

Stott, G. H., and R. J. Williams. 1969. Causes of low breeding efficiency in dairy cattle associated with seasonal high temperatures. J. Dairy Sci. 45:1369.

Wilson, S. J., R. S. Marion, J. N. Spain, D. E. Spiers, D. H. Keisler and M. C. Lucy. 1998. Effects of controlled heat stress on ovarian function of dairy cattle. 1. Lactating cows. J. Dairy Sci. 81:2124-2131.

Wolfenson, D. Z., Z. Roth, and R. Meidan. 2000. Impaired reproduction in heat-stressed cattle: basic and applied aspects. Anim. Reprod. Sci. 60-61:535-547.

Yousef, M. K. 1985. Thermoneutral zone. In: Stress Physiology in Livestock, M. K. Yousef (ed.), Vol. I, CRC Press, Boca Raton, FL. $47-54$.

ZIPFind 2000. Available: http://ZIPFind.net. Accessed July 20th, 2000 . 